OPEN ACCESS

Edited by:

Shijun $\mathrm{Hu}$,

Soochow University, China

Reviewed by:

Joseph Isaac Shapiro,

Marshall University, United States

Philippe Bourin,

Independent Researcher, Toulouse,

France

*Correspondence:

Qianhong $\mathrm{Li}$

qianhong.li@louisville.edu

Specialty section:

This article was submitted to

Stem Cell Research,

a section of the journal

Frontiers in Cell and Developmental

Biology

Received: 01 February 2021

Accepted: 22 April 2021

Published: 26 May 2021

Citation:

Bolli RAR, Arshia A, Hassan SA, Dasari C, Nong Y, Guo Y, Tomlin AA and Li Q (2021) Cardiac

Mesenchymal Cells Cultured at Physiologic Oxygen Tension Have Superior Therapeutic Efficacy in Heart

Failure Caused by Myocardial Infarction.

Front. Cell Dev. Biol. 9:662415. doi: 10.3389/fcell.2021.662415

\section{Cardiac Mesenchymal Cells Cultured at Physiologic Oxygen Tension Have Superior Therapeutic Efficacy in Heart Failure Caused by Myocardial Infarction} Robi A. R. Bolli, Asma Arshia, Syed A. Hassan, Chandrashekhar Dasari, Yibing Nong,
Yiru Guo, Alex A. Tomlin and Qianhong Li*

Department of Medicine, Institute of Molecular Cardiology, University of Louisville, Louisville, KY, United States

Stem/progenitor cells are usually cultured at atmospheric $\mathrm{O}_{2}$ tension (21\%); however, since physiologic $\mathrm{O}_{2}$ tension in the heart is $\sim 5 \%$, using $21 \% \mathrm{O}_{2}$ may cause oxidative stress and toxicity. Cardiac mesenchymal cells (CMCs), a newly discovered and promising type of progenitor cells, are effective in improving left ventricle (LV) function after myocardial infarction (MI). We have previously shown that, compared with $21 \%$ $\mathrm{O}_{2}$, culture at $5 \% \mathrm{O}_{2}$ increases $\mathrm{CMC}$ proliferation, telomerase activity, telomere length, and resistance to severe hypoxia in vitro. However, it is unknown whether these beneficial effects of $5 \% \mathrm{O}_{2}$ in vitro translate into greater therapeutic efficacy in vivo in the treatment of heart failure. Thus, murine CMCs were cultured at $21 \%$ or $5 \% \mathrm{O}_{2}$. Mice with heart failure caused by a 60 -min coronary occlusion followed by 30 days of reperfusion received vehicle, $21 \%$ or $5 \% \mathrm{O}_{2}$ CMCs via echocardiography-guided intraventricular injection. After 35 days, the improvement in LV ejection fraction effected by $5 \% \mathrm{O}_{2}$ CMCs was $>3$ times greater than that afforded by $21 \% \mathrm{O}_{2}$ CMCs (5.2 vs. 1.5 units, $P<0.01$ ). Hemodynamic studies (Millar catheter) yielded similar results both for load-dependent (LV dP/dt) and load-independent (end-systolic elastance) indices. Thus, two independent approaches (echo and hemodynamics) demonstrated the therapeutic superiority of $5 \% \mathrm{O}_{2}$ CMCs. Further, $5 \% \mathrm{O}_{2} \mathrm{CMCs}$, but not $21 \% \mathrm{O}_{2}$ CMCs, significantly decreased scar size, increased viable myocardium, reduced LV hypertrophy and dilatation, and limited myocardial fibrosis both in the risk and noninfarcted regions. Taken together, these results show, for the first time, that culturing CMCs at physiologic (5\%) $\mathrm{O}_{2}$ tension provides superior therapeutic efficacy in promoting cardiac repair in vivo. This concept may enhance the therapeutic potential of CMCs. Further, culture at $5 \% \mathrm{O}_{2}$ enables greater numbers of cells to be produced in a shorter time, thereby reducing costs and effort and limiting cell senescence. Thus, the present study has potentially vast implications for the field of cell therapy.

Keywords: stem cells, heart failure, myocardial infarction, cardiac function, cardiac repair, cardiac mesenchymal cells, physiologic oxygen tension 


\section{INTRODUCTION}

Cell therapy is emerging as a potentially useful approach to the treatment of heart failure. Cardiac mesenchymal cells (CMCs), a newly discovered and promising type of progenitor cells recently isolated from the heart of mice, rats, and humans, have shown significant efficacy in improving cardiac function in mice and rats that underwent myocardial infarction (MI) resulting in heart failure (Guo et al., 2017; Wysoczynski et al., 2017). In addition to their efficacy, CMCs offer several advantages over other cell types, including the fact that their isolation and expansion are considerably simpler and less expensive than other cardiacderived cells (Wysoczynski et al., 2017).

Since the establishment of the first cell line culture for mouse fibroblasts in 1943 (Earle et al., 1943), cell culture at normoxic conditions (atmospheric oxygen tension, 21\%) has been the standard method used by almost all investigators that use stem or progenitor cells in preclinical and in clinical studies. However, physiologic oxygen tension in living organs is only $3-12 \%$ (MasBargues et al., 2019); in the heart, it is 5\% (Roy et al., 2003). This raises the concern that culturing cells at $21 \% \mathrm{O}_{2}$ may cause toxicity due to oxidative stress. Furthermore, cells grown at $21 \% \mathrm{O}_{2}$ may not survive well in the microenvironment of the heart where oxygen tension is $5 \%$, and particularly in the scarred regions where $\mathrm{O}_{2}$ is very low. Indeed, many studies in animal models have documented that the vast majority ( $>95 \%$ ) of cells transplanted in the heart die or vanish shortly after administration (Wysoczynski et al., 2018). Previous studies of cells other than CMCs suggest that culturing cells at physiological oxygen tension is beneficial (Mohyeldin et al., 2010; Drela et al., 2014; Jagannathan et al., 2016). We have recently demonstrated that the use of physiologic (5\%) oxygen tension to culture CMCs in vitro improves cell morphology, markedly decreases cell size, markedly increases cell proliferation, and greatly enhances cell resistance to severe hypoxic stress (Bolli et al., 2021). However, it is unknown whether these beneficial effects of $5 \%$ oxygen in vitro translate into greater therapeutic efficacy in vivo in the treatment of heart failure.

The present investigation was undertaken in follow-up to our previous work in vitro (Bolli et al., 2021). The goal of this study was to directly compare the therapeutic efficacy of CMCs cultured at physiologic oxygen tension (5\%) with that of CMCs cultured with the commonly used atmospheric oxygen tension $\left(21 \% \mathrm{O}_{2}\right)$ in a mouse model of heart failure caused by an old MI. We found that CMCs cultured at $5 \% \mathrm{O}_{2}$ had significantly greater therapeutic efficacy; that is, they produced a greater improvement in left ventricular (LV) function, a greater increase in viable myocardium, and a greater decrease in myocardial fibrosis.

\section{MATERIALS AND METHODS}

\section{Ethics Statement}

All animal procedures were performed in accordance with the Guide for the Care and Use of Laboratory Animals (Department of Health and Human Services, Publication No. [NIH] 86-23) and with the guidelines of the Animal Care and Use Committee of the University of Louisville, School of Medicine (Louisville, KY, United States). The protocol was approved by the Institutional Animal Care and Use Committee of the University of Louisville. All the surgical procedures, measurements of LV function (echocardiography and hemodynamic studies) and pathological analyses were performed by investigators double-blinded to treatment allocation.

\section{Isolation of Murine CMCs}

Male C57BL/6J mice (The Jackson Laboratory), $12 \pm 0.5$ weeks old, were euthanized by sodium pentobarbital injection (100 mg/kg, i.p.). The hearts were excised, rinsed with PBS $(\mathrm{pH} 7.4)$ at room temperature, minced into small pieces, and then enzymatically dissociated with Collagenase II $(5 \mu \mathrm{g} / \mathrm{mL}$ in PBS, $\geq 125$ units per mg dry weight; Worthington) via gentle agitation at $37^{\circ} \mathrm{C}$ for $45 \mathrm{~min}$. After Collagenase II inactivation with DMEM/F12 medium containing 10\% FBS, cells were centrifuged at $600 \mathrm{~g}$ for $10 \mathrm{~min}$ at room temperature. The collected cell pellet was suspended in growth medium consisting of DMEM/F12 (Invitrogen), 10\% FBS (Seradigm, VWR), bFGF (10 ng/ml, Invitrogen), EGF (10 ng/ml, Invitrogen), ITS (insulin/transferrin/selenium, Invitrogen), glutamine (Invitrogen), and penicillin streptomycin solution (Invitrogen). A single-cell suspension was plated into culture plates. The non-adherent cells were removed $2 \mathrm{~h}$ after initial plating, and the attached cells were gently rinsed with PBS and then continuously cultured in new growth medium. Collected floating cells were plated into new cell culture plates and cultured for the next $2 \mathrm{~h}$. The procedure was repeated three more times at 24,48 , and $72 \mathrm{~h}$, respectively. A total of five fractions were collected after myocardial digestion. The cell fractions that attached within the first 2 and $4 \mathrm{~h}$ were discarded, as most of them were cardiac fibroblasts, which can quickly attach on the culture plates, whereas the cells that attached on the culture plates at 24, 48, and $72 \mathrm{~h}$ were designated as cardiac mesenchymal cells (CMCs), whose properties and function have been identified previously (Wysoczynski et al., 2017).

\section{Murine CMC Culture}

Murine CMCs were cultured in growth medium (Wysoczynski et al., 2017; Schulman et al., 2018). Under a microscope, when cells reached $\sim 80 \%$ confluence in the culture plate, cell images were acquired to monitor changes in cell morphology. Then, cells from one 100-mm culture plate were digested by trypsinization, counted with a hemocytometer under a microscope, split and seeded into new $100-\mathrm{mm}$ culture plates at $5,000 \mathrm{cells} / \mathrm{cm}^{2}$. Beginning at passage 2 , cells were cultured either in a $21 \% \mathrm{O}_{2}$ or $5 \% \mathrm{O}_{2}$ incubator supplied with $5 \% \mathrm{CO}_{2}$ at $37^{\circ} \mathrm{C}$. Cells at passages 5-6 were employed for cell transplantation in vivo. To control the quality of the cell batch, the same batch of cells at passage 2 characterized previously (Wysoczynski et al., 2017) was used to develop $21 \%$ and $5 \% \mathrm{O}_{2} \mathrm{CMCs}$ for the in vitro studies of cell competence and functional properties (Bolli et al., 2021). The same batch of these $21 \%$ and $5 \% \mathrm{O}_{2}$ CMCs used in those in vitro studies was employed for the current study in vivo. In all experiments, CMCs were passaged $<7$ times (Bolli et al., 2021). 


\section{Murine Model of Heart Failure Caused by an Old MI}

C57BL/6J female mice (weight, $22.4 \pm 0.4$ g; age 14-15 weeks) purchased from The Jackson Laboratory (Bar Harbor, ME, United States) were used. Mice were maintained in microisolator cages under specific pathogen-free conditions in a room with a temperature of $24^{\circ} \mathrm{C}, 55-65 \%$ relative humidity, and a 12 -h lightdark cycle. Mice were anesthetized with sodium pentobarbital $(60 \mathrm{mg} / \mathrm{kg}$ i.p.) and ventilated using carefully selected parameters. The chest was opened through a midline sternotomy, and a nontraumatic balloon occluder was implanted around the mid-left anterior descending coronary artery using an 8-0 nylon suture. To prevent hypotension, blood from a donor mouse was given at serial times during surgery. Rectal temperature was carefully monitored and maintained between 36.7 and $37.3^{\circ} \mathrm{C}$ throughout the experiment. In all groups, MI was produced by a $60-\mathrm{min}$ coronary occlusion followed by reperfusion (Figure 1). Successful performance of coronary occlusion and reperfusion was verified by visual inspection (i.e., by noting the development of a pale color in the distal myocardium after inflation of the balloon and the return of a bright red color due to hyperemia after deflation) and by observing ST-segment elevation and widening of the QRS on the ECG during ischemia and their resolution after reperfusion). Mice were then followed for 65 days (Guo et al., 2017; Wysoczynski et al., 2017; Guo et al., 2020).

\section{Echocardiography-Guided Intraventricular CMC Transplantation}

Thirty days after MI, mice were randomly allocated to vehicle or different cell-treated groups. CMC or vehicle transplantation was performed using a Vevo 2100 Imaging System (VisualSonics, Inc.) equipped with a $30-\mathrm{MHz}$ transducer, a Vevo Image Station with Injection Mount, and micro-manipulation controls (Guo et al., 2017; Nong et al., 2020). Mice were reanesthetized with isoflurane ( $3 \%$ for induction, $1.5 \%$ for maintenance). The anterior chest was shaved and mice were placed on the imaging table in the right lateral decubitus position with the left lateral side facing the injection mount. After a good long-axis view of left ventricle was procured, the transducer was turned 90 degrees clockwise. The left ventricle was scanned in the short-axis view from apex to base to determine the optimal site for needle insertion. To prevent bleeding from the LV wall, it is crucial to find a site that avoids the infarct scar and coronary arteries. Under real-time B-mode view, a 0.5 -inch $30 \mathrm{G}$ needle connected to a $1.0 \mathrm{ml}$ syringe was carefully inserted from the left lateral side of the chest and advanced into the center of the LV cavity. Successful penetration of the LV cavity was indicated by a small reflux of bright red blood from the needle into the syringe tip. CMCs $\left(1 \times 10^{6}\right.$ cells in $200 \mu \mathrm{l}$ of PBS) or vehicle $(200 \mu \mathrm{l}$ of PBS) were infused at a steady rate of $2.2 \mu \mathrm{l} / \mathrm{s}$ over $90 \mathrm{~s}$. After the infusion, the needle was quickly withdrawn from the left ventricle. Using a rectal temperature probe, body temperature was controlled in the range of $37 \pm 0.2^{\circ} \mathrm{C}$, and the electrocardiogram and respiration were monitored carefully during the whole procedure. Mice were allowed to recover in a temperature-controlled area (Guo et al., 2017).

\section{Echocardiographic Studies}

The echocardiographic studies were performed using the Vevo 2100 Imaging System (VisualSonics, Inc.) equipped with a 30$\mathrm{MHz}$ transducer, as previously described (Li Q. et al., 2011). Serial echocardiograms were obtained at 3 days after the 60 -min occlusion (Post-MI), 30 days after MI (before treatment, Pre$\mathrm{Rx}$ ), and 35 days after treatment (After-Rx) (Figure 1) under isoflurane anesthesia ( $3 \%$ for induction, $1 \%$ for maintenance).

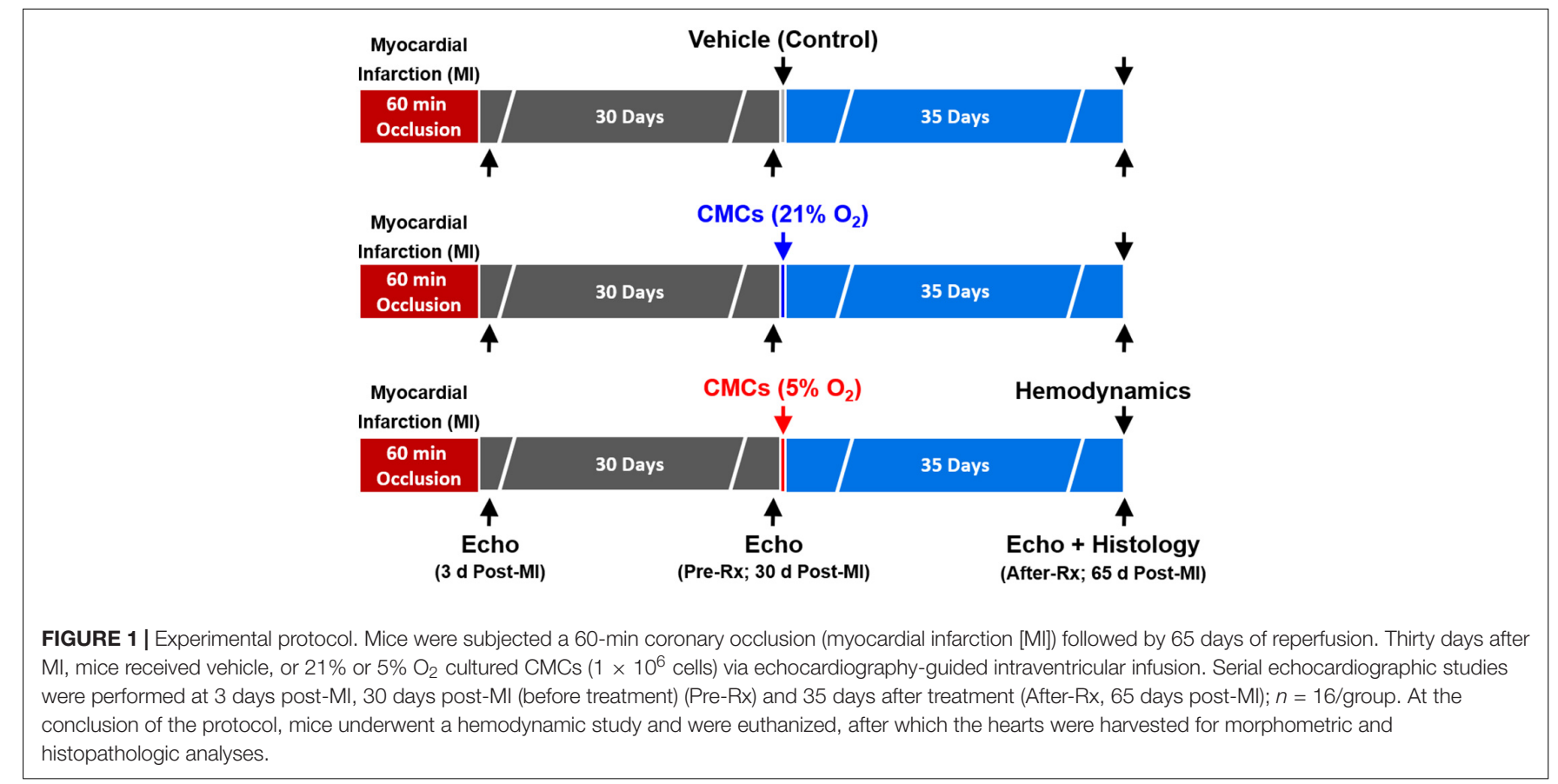


Using a rectal temperature probe, body temperature was carefully maintained at $37 \pm 0.2^{\circ} \mathrm{C}$ throughout the study. The parasternal long axis and parasternal short-axis views were used to obtain 2D mode images for the measurement of LV mass, enddiastolic and end-systolic LV volume (LVEDV and LVESV), stroke volume (SV), and EF, as previously described (Dawn et al., 2006; Li Q. et al., 2011). Digital images were analyzed off-line by blinded observers using the Vevo 2100 software. Measurements were performed according to the American Society for Echocardiography (Gottdiener et al., 2004; Mehra et al., 2018). At least three measurements were acquired and averaged for each parameter (Gao et al., 2011).

\section{Hemodynamic Studies}

To avoid any potential effects of isoflurane anesthesia on cardiac function, hemodynamic studies were performed 4 days after the final echocardiography studies and just before euthanasia, as previously reported (Guo et al., 2017; Mehra et al., 2018). Mice were anesthetized with sodium pentobarbital $(60 \mathrm{mg} / \mathrm{kg}$ i.p.), intubated, and ventilated with a positive pressure ventilator (Hugo-Sachs Electronik D-79232 [Germany]; ventilation rate, 105/min; tidal volume $10.3 \mu \mathrm{l} / \mathrm{g}$ ). Rectal temperature was kept at $37 \pm 0.2^{\circ} \mathrm{C}$. A 1.0 French pressure-volume (PV) catheter (PVR1035, Millar Instruments) was inserted into the left ventricle via the right carotid artery. The position of the catheter was carefully adjusted until typical and stable PV loop signals were acquired. After $30 \mathrm{~min}$ of stabilization, the PV signals were recorded continuously with an MPVS ULTRA PressureVolume Unit (Millar Instruments) coupled with a Powerlab 16/30 converter (AD Instruments), stored, and displayed on a computer with LabChart 7.0 software (AD Instruments). Inferior vena cava occlusions were performed with external compression to produce variably loaded beats for determination of the end-systolic PV relation and other derived constructs of LV performance. Parallel conductance from surrounding structures was calculated by a bolus injection of $5 \mu \mathrm{l}$ of $30 \%$ $\mathrm{NaCl}$ through the jugular vein. Echocardiography-derived SV was used as outside reference for alpha calibration for LV volume. All hemodynamic data analyses were performed off-line using LabChart 7.0 software by an investigator blinded to the treatment allocation (Li Q. et al., 2011).

\section{Histological Studies}

At the conclusion of the protocol, the heart was arrested in diastole by an i.v. injection of $0.15 \mathrm{ml}$ of $\mathrm{CdCl}_{2}(100 \mathrm{mM})$, excised, and perfused retrogradely at $60-80 \mathrm{mmHg}$ (LVEDP $=8 \mathrm{mmHg})$ with heparinized PBS for $2 \mathrm{~min}$, followed by $10 \%$ neutral buffered formalin solution for $15 \mathrm{~min}$. The heart was then sectioned into three slices from apex to base, fixed in formalin for $24 \mathrm{~h}$, and subjected to tissue processing and paraffin embedding. Paraffin-embedded LV blocks were sectioned at a thickness of $4 \mu \mathrm{m}$ for histological studies (Li Q. et al., 2011). Morphometric parameters, including LV cavity area, total LV area, risk region area, scar area, LV wall thickness, and infarct expansion index were measured in sections stained with Masson's trichrome as described previously (Tang et al., 2016). Myocardial collagen content was quantitated on picrosirius red-stained heart images acquired with polarized light microscopy by determining collagen area per $\mathrm{mm}^{2}$ of risk region or non-infarcted region (Tang et al., 2018). All acquired images were analyzed using NIH ImageJ software (version 1.52a) and measurements were averaged from three slides (trichrome) or two slides (collagen) per heart (Guo et al., 2017; Tang et al., 2018).

\section{Statistical Analysis}

The statistical methods were similar to those previously used by our group (Bennett et al., 1987; Triana et al., 1991; Li et al., 1993, 2001; Tang et al., 1996; Dawn et al., 2008). Data are presented as mean \pm SEM. Data were analyzed with one-way repeated measures ANOVA as well as with one-way ANOVA for normally distributed data, or Kruskal-Wallis one-way analysis of variance on ranks for data that are not normally distributed, as appropriate, followed by unpaired Student's $t$-tests with the Bonferroni correction. A $P<0.05$ was considered statistically significant. All statistical analyses were performed using the SigmaStat software system $(3.5 \mathrm{~V})$.

\section{RESULTS}

\section{Exclusions}

A total of 96 mice were used for this study. Forty-one mice died during or shortly after the surgical procedure of opening the chest and producing a 60-min coronary occlusion to induce MI. Seven mice were excluded because of technical problems, including body temperature out of normal range $(n=1)$, balloon occluder malfunction $(n=1)$, bleeding after echocardiography-guided LV cell injection $(n=2)$, and poor echocardiographic images for data analysis $(n=3)$. Thus, a total of 48 mice were included in the final analysis.

\section{Fundamental Physiological Parameters}

During the echocardiographic studies, heart rate and body temperature (fundamental physiological parameters that may impact myocardial function) were similar in the three groups. The heart rate was $516 \pm 10$ beats $/ \mathrm{min}$ in the vehicle group, $520 \pm 11$ beats $/ \mathrm{min}$ in the $21 \% \mathrm{O}_{2}$ cultured CMC group, and $495 \pm 7$ beats $/ \mathrm{min}$ in the $5 \% \mathrm{O}_{2}$ cultured CMC group. By experimental design, rectal temperature remained within a narrow, physiologic range $\left(36.9-37.1^{\circ} \mathrm{C}\right)$ in all three groups (Table 1).

\section{Effect of Physiologic Oxygen Tension on CMCs}

After they were isolated from the mouse heart, CMCs were cultured in an incubator supplied either with $21 \%$ or $5 \% \mathrm{O}_{2}$ beginning at passage 2. As illustrated in Figure 2A, CMCs cultured at $21 \% \mathrm{O}_{2}$ for 4 days at passage 5 showed poor morphology and exhibited lower cell density; cells were large and elongated with varied shapes. In contrast, CMCs cultured at 5\% $\mathrm{O}_{2}$ for 4 days at passage 5 were small, showed higher density, and had round/oval and more uniform shape (Figure 2B). These observations are consistent with our previous studies 
TABLE 1 | Rectal temperature and heart rate on the days of echocardiography assays.

\begin{tabular}{lccc}
\hline & Post MI & Pre Rx & After Rx \\
\hline & (3 days after MI) & (30 days after MI) & (35 days after Rx) \\
\hline Temperature ( $\left.{ }^{\circ} \mathbf{C}\right)$ & & & \\
Vehicle Group & $36.9 \pm 0.1$ & $37.1 \pm 0.1$ & $36.9 \pm 0.0$ \\
$21 \% \mathrm{O}_{2}$ CMC Group & $36.9 \pm 0.1$ & $36.9 \pm 0.0$ & $37.0 \pm 0.0$ \\
$5 \% \mathrm{O}_{2} \mathrm{CMC}$ Group & $37.0 \pm 0.1$ & $37.0 \pm 0.0$ & $37.0 \pm 0.0$ \\
Heart rate (beats/min) & & & \\
Vehicle Group & $516 \pm 10$ & $487 \pm 9$ & $483 \pm 9$ \\
$21 \% \mathrm{O}_{2} \mathrm{CMC}$ Group & $520 \pm 11$ & $499 \pm 8$ & $495 \pm 10$ \\
$5 \% \mathrm{O}_{2}$ CMC Group & $495 \pm 7$ & $482 \pm 9$ & 495 \\
\hline
\end{tabular}

Measurements of rectal temperature and heart rate were acquired during the echocardiographic studies ( $n=16 /$ group). Data are means \pm SEM.

(Bolli et al., 2021) and suggest that physiological 5\% $\mathrm{O}_{2}$ is beneficial to CMC function.

\section{Effect of CMCs Cultured at Physiologic Oxygen Tension on LV Function Measured by Echocardiography}

Echocardiographic studies were performed 3 days after MI (Post$\mathrm{MI}$ ), 30 days after MI (before treatment) (Pre-Rx), and 35 days after treatment (After-Rx, 65 days after MI). According to our inclusion criteria, only mice with severe LV dysfunction, i.e., $\mathrm{EF}<35 \%$ at 30 days after MI, were included in the study (Figure 3). Representative echocardiographic images acquired from a mouse in the $5 \% \mathrm{O}_{2} \mathrm{CMC}$ group before $\mathrm{MI}, 30$ days after MI (Pre-Rx), and 35 days after cell treatment (After-Rx), are presented in Figure 2C.

As expected, the vehicle group showed a significant, progressive deterioration in LV function, with the average EF decreasing from 31.5 to $28.4 \%(P<0.05)$ in the 30 -day interval between 3 days post-MI and right before vehicle injection (Pre$\mathrm{Rx})$; in this group, LV EF continued to decline from 28.4 to $27.4 \%(P<0.05)$ in the subsequent 35-day interval after vehicle injection (After-Rx) (Figure 4A).

At 30 days post-MI (before treatment) (Pre-Rx), there were no significant differences among the three groups with respect to LV end-diastolic volume (LVEDV), end-systolic volume (LVESV), stroke volume (SV), and EF (Figures 4A,B, 5A-C), indicating that the severity of post-MI LV remodeling and dysfunction was comparable in all groups. The pronounced LV dilatation in all groups, as shown by the increase in LVEDV and LVESV (Figures 5D,E), demonstrates that this murine model exhibits significant LV remodeling after MI. Thirty-five days after treatment (After-Rx), a significant improvement in LV EF was noted both in the $21 \%$ and $5 \% \mathrm{O}_{2}$ CMC groups compared with that in the vehicle group; however, the improvement was significantly more robust in the $5 \% \mathrm{O}_{2} \mathrm{CMC}$ group. This is

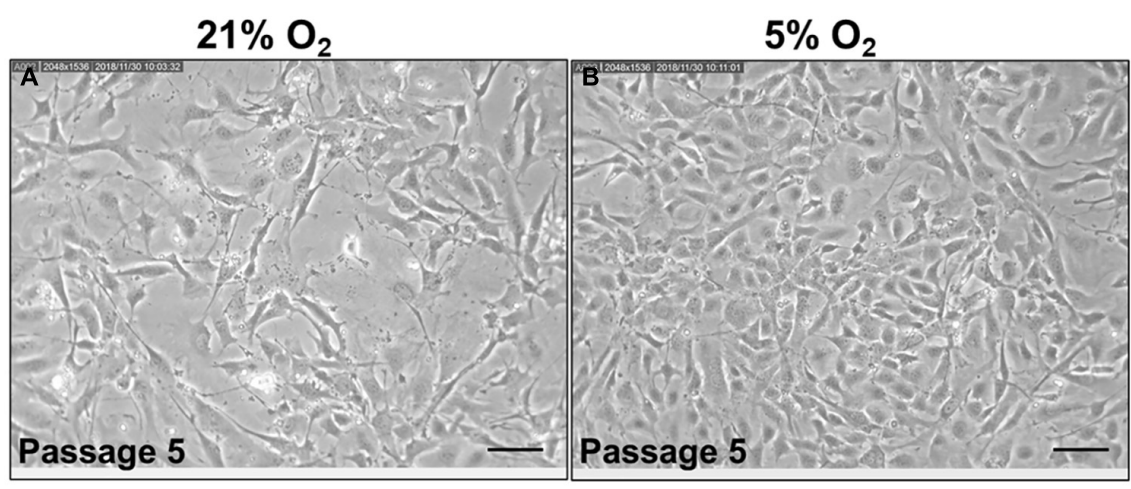

C Normal Heart (Before MI)

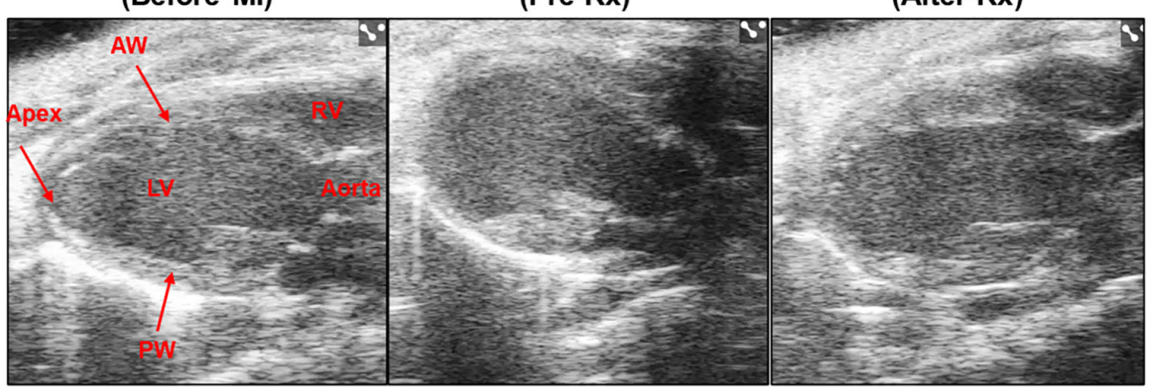

FIGURE 2 | Effect of CMCs cultured at 5\% oxygen tension on cardiac function after MI. Representative microscopic images of CMCs acquired from $21 \%$ (A) and $5 \%$ (B) $\mathrm{O}_{2}$ cultured CMCs at passage five under magnification $\times 200$. Scale bars, $100 \mu \mathrm{m}$. (C) Representative echocardiography B-mode long-axis images obtained before $\mathrm{Ml}\left(\right.$ left), 30 days after MI (Pre-Rx) (middle) and 35 days after $5 \% \mathrm{O}_{2}$ cultured $\mathrm{CMC}$ treatment (After-Rx) (right). LV, left ventricle; RV, right ventricle; AW, anterior wall; PW, posterior wall. 


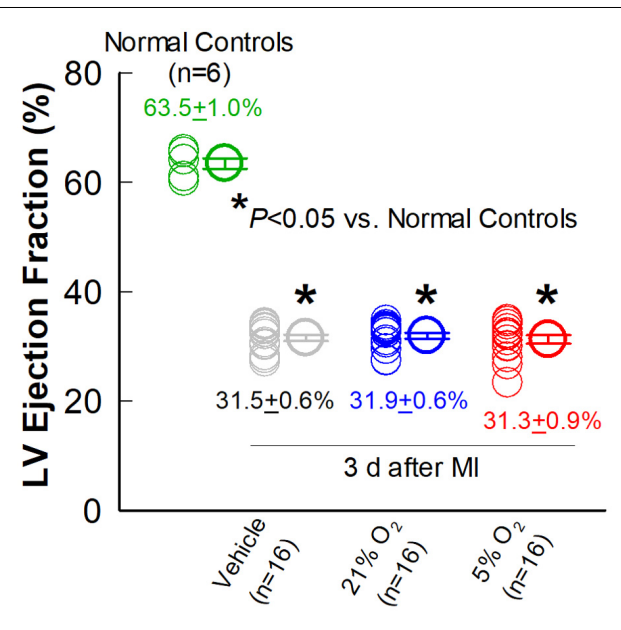

FIGURE 3 | Comparison of LV EF three days after MI. Echocardiographic measurements of LV EF were performed in the vehicle, $21 \% \mathrm{O}_{2}$, and $5 \% \mathrm{O}_{2}$ CMC groups ( $n=16 /$ group) 3 days after $\mathrm{Ml}$ (in the absence of cell treatment) and in normal, age-matched control mice that did not undergo surgery $(n=6)$. Data are means \pm SEM. ${ }^{*} P<0.05$ vs. normal control group.

demonstrated by the fact that in this group, the increase in LV EF from pretreatment values (Pre-Rx) to 35 days after treatment (After-Rx) was $5.2 \pm 0.9 \%$ (absolute units), whereas in the $21 \%$ $\mathrm{O}_{2}$ CMC group it was only $1.5 \pm 0.7 \%\left(P<0.05\right.$ vs. the $5 \% \mathrm{O}_{2}$ CMC group) (in the vehicle group, LV EF actually decreased by $-1.0 \pm 0.5 \%)$ (Figure 4C). As a result, at 35 days after treatment LV EF was significantly $(P<0.05)$ greater in the $5 \% \mathrm{O}_{2} \mathrm{CMC}$ group compared with the $21 \% \mathrm{O}_{2} \mathrm{CMC}$ group (Figures $4 \mathbf{A}, \mathbf{B}$ ). A similar pattern was also observed in $\triangle \mathrm{LVEDV}, \triangle \mathrm{LVESV}$ and $\triangle$ SV: both $21 \% \mathrm{O}_{2} \mathrm{CMCs}$ and $5 \% \mathrm{O}_{2}$ CMCs improved LVEDV, LVESV and SV compared with vehicle (Figures 5D-F), but the improvement in the $5 \% \mathrm{O}_{2} \mathrm{CMC}$ group was statistically greater than that in the $21 \% \mathrm{O}_{2} \mathrm{CMC}$ group (Figures 5D,E). One-way repeated measures ANOVA showed that among the three groups, only $5 \% \mathrm{O}_{2}$ CMCs significantly improved LV EF (Figure 4A) and LV remodeling (EDV and ESV; Figures 5A,B) at 35 days after treatment as compared with pre-treatment values.

Taken together, these results indicate that $5 \% \mathrm{O}_{2} \mathrm{CMCs}$ are superior to $21 \% \mathrm{O}_{2} \mathrm{CMCs}$ in improving the function of the failing murine heart after a 30-day old MI and that the use of physiologic oxygen tension (5\%) to culture CMCs increases their therapeutic efficacy.

\section{Effect of CMCs Cultured at Physiologic Oxygen Tension on LV Function Measured by Hemodynamic Studies}

To prevent any after-effects of the anesthesia used during the echocardiographic assessment 35 days after cell administration, a 4-day interval was allowed between echocardiographic and hemodynamic measurements; thus, the hemodynamic studies were performed just before euthanasia, 39 days after vehicle or cell administration. At this time, all LV functional parameters were markedly depressed in the vehicle, $21 \%$ and $5 \% \mathrm{O}_{2}$
CMC groups (Figure 6). Figure 6A illustrates representative $\mathrm{LV}$ pressure-volume (P-V) loops acquired in the vehicle, $21 \%$ and $5 \% \mathrm{O}_{2} \mathrm{CMC}$ groups. The leftward shift of the volume signal and increased amplitude of the pressure signal in the $\mathrm{P}-\mathrm{V}$ loops (resulting in a steeper end-systolic pressure-volume relationship) in the $5 \% \mathrm{O}_{2} \mathrm{CMC}$-treated mouse are indicative of reduced LV operating volumes and enhanced contractility. Compared with the vehicle group, hemodynamic parameters were improved in both cell-treated groups, but the improvement was more robust in the $5 \% \mathrm{O}_{2} \mathrm{CMC}$ group than in the $21 \%$ $\mathrm{O}_{2}$ CMC group. This was the case not only for load-dependent (LV EF and LV dP/dt) but also for load-independent (endsystolic elastance and Tau) indices of LV function (Figures 6E$\mathbf{H})$. Both LV dP/dt and end-systolic elastance were significantly greater in the $5 \% \quad \mathrm{O}_{2} \mathrm{CMC}$ group than in the $21 \% \mathrm{O}_{2}$ CMC group, and EF was improved in the former but not in the latter (Figures 6E-G). Thus, two independent methods of functional assessment (echocardiography and hemodynamic studies) consistently demonstrated that the functional benefits offered by $5 \% \mathrm{O}_{2}$ CMC treatment are superior to those of $21 \%$ $\mathrm{O}_{2}$ CMC treatment.

\section{Effect of CMCs Cultured at Physiologic Oxygen Tension on LV Structure}

A hallmark of ischemic cardiomyopathy is the presence of compensatory hypertrophy in the surviving myocardium. As shown in Table 2, LV weight was significantly increased in vehicle-treated mice compared with normal controls, indicating the development of compensatory LV hypertrophy after MI in this murine model of chronic ischemic cardiomyopathy. Importantly, the ratios of LV weight to body weight and LV weight to tibial length were significantly reduced in the $5 \% \mathrm{O}_{2}$ CMC group $(n=12, P<0.05)$ as compared with the vehicle group ( $n=12$, Table 2 ), demonstrating that administration of $5 \% \quad \mathrm{O}_{2}$ grown CMCs ameliorated LV hypertrophy. In contrast, these parameters did not differ significantly between the $21 \% \quad \mathrm{O}_{2}$ and vehicle groups. Although the differences among groups were not statistically significant, both the ratios of lung weight to body weight and lung weight to tibial length were nominally lower in the $5 \% \mathrm{O}_{2} \mathrm{CMC}$ group (but not in the $21 \% \mathrm{O}_{2} \mathrm{CMC}$ group) compared with the vehicle group, suggesting that $5 \% \mathrm{O}_{2}$ grown CMCs may alleviate pulmonary congestion.

The effects of CMC transplantation on LV remodeling were further assessed by Masson's trichrome staining. Figure 7 shows representative Masson's trichrome-stained myocardial sections from the vehicle, $21 \%$ and $5 \% \mathrm{O}_{2}$ CMC groups. Scar tissue and viable myocardium are identified in blue and red, respectively. There were no appreciable differences among the three groups with respect to the size of the region at risk (Figure $7 \mathbf{B}$ ), suggesting that the magnitude of the ischemic insult was comparable in all groups. This is confirmed by the fact that LV EF was similar in all groups after MI, as shown in Figure 4B. Compared with the vehicle group, the 5\% $\mathrm{O}_{2}$ CMC-treated hearts exhibited a decrease in scar size and a concomitant increase in the amount of viable myocardium in the region at 

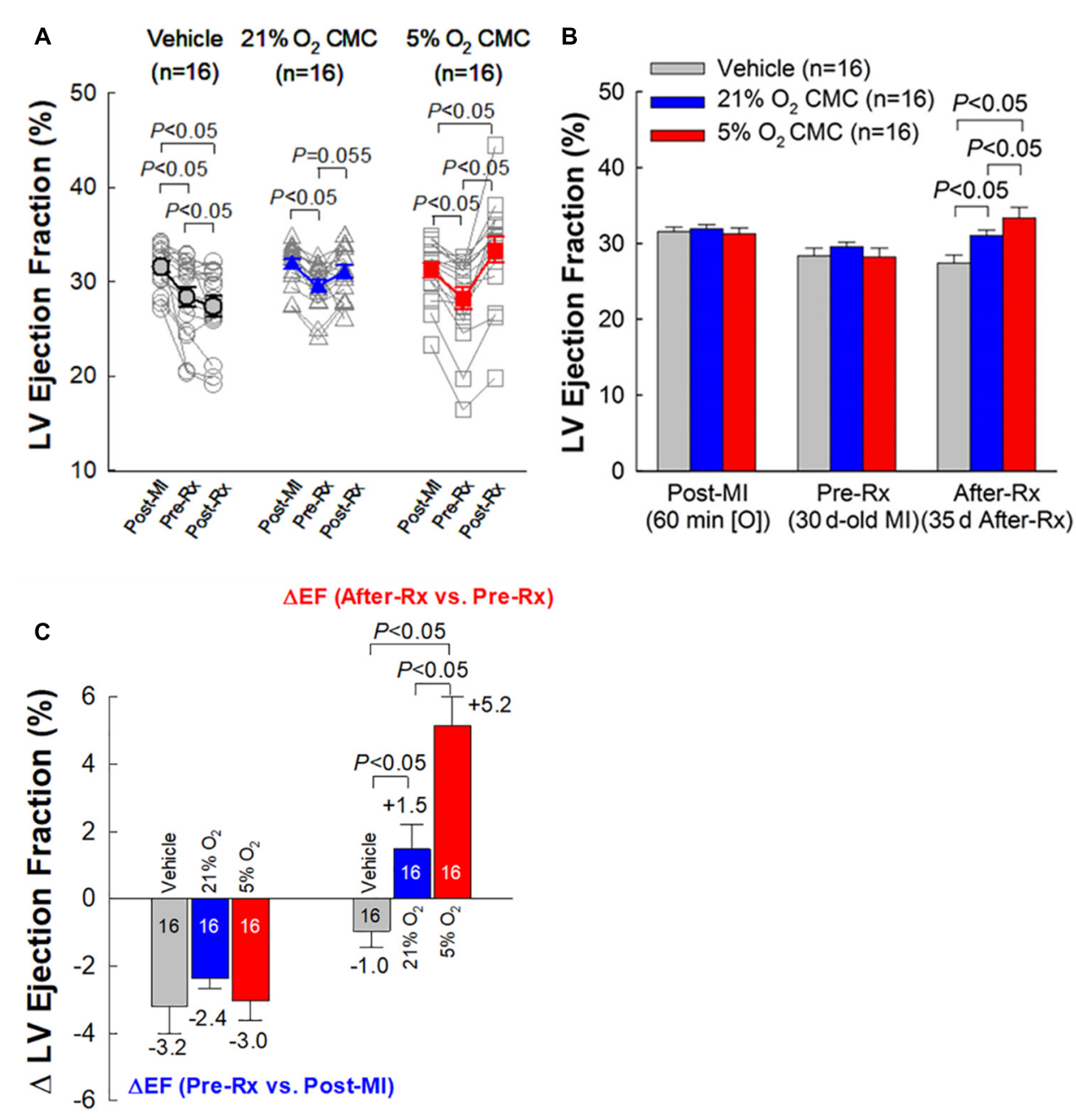

FIGURE 4 | Echocardiographic assessment of LV EF. (A) Values of LV EF acquired from each individual mouse at each time-point. (B) Mean values of LV EF at each time-point. (C) Changes in LV EF. On the left are depicted the changes in LV EF (absolute units) between 30 days after MI (before treatment) (Pre-Rx) and 3 days after MI (Post-MI). On the right are depicted the changes in LV EF (absolute units) between 35 days after treatment (After-Rx) and 30 days after MI (before treatment) (Pre-Rx). $n=16$ /group. Data are mean \pm SEM.

risk (Figure 7B), concomitant with an increase in LV anterior wall (infarct wall) thickness, a decrease in LV posterior wall (non-infarcted wall) thickness, and a decrease in LV expansion index (which is indicative of reduced LV dilatation) (Figure 7C). In contrast, the $21 \% \mathrm{O}_{2} \mathrm{CMC}$-treated hearts did not differ significantly from the vehicle-treated hearts with respect to scar size, viable myocardium, or non-infarcted wall thickness (Figures 7B,C). The increased amount of viable myocardium may have contributed to the increased cardiac function in mice that received $5 \% \mathrm{O}_{2} \mathrm{CMCs}$.

\section{Effect of CMCs Cultured at Physiologic Oxygen Tension on Myocardial Collagen Content}

One of the features of the failing heart is fibrosis, i.e., excess deposition of collagen in the extracellular matrix. We performed quantitative analysis of collagen content in the heart using picrosirius red staining followed by imaging with polarized light microscopy (Figures 8A-C). Collagen content was evaluated based on stained pixel density using the $\mathrm{NIH}$ Image software and expressed as a percentage of the risk or non-infarcted region. In the risk region (which is the sum of the infarcted and border regions), collagen content tended to be less in the $21 \% \mathrm{O}_{2}$ CMC group compared with the vehicle group but the difference was not statistically significant (Figure 8D). In contrast, collagen content in the risk region was significantly reduced in hearts treated with $5 \% \mathrm{O}_{2}$ grown CMCs as compared with the vehicle group $(40.1 \pm 3.8 \%$ of risk region vs. $51.6 \pm 4.7 \%$, respectively, $P<0.05$; Figure 8D). Similarly, in the non-infarcted region, collagen content was significantly less in the $5 \% \mathrm{O}_{2}$ CMCtreated group ( $9.4 \pm 2.1 \%$ of non-infarcted region) as compared with the vehicle group $(15.7 \pm 1.9 \%, P<0.05$; Figure $8 \mathrm{E})-$ a relative reduction of nearly $50 \%$. In contrast, collagen 

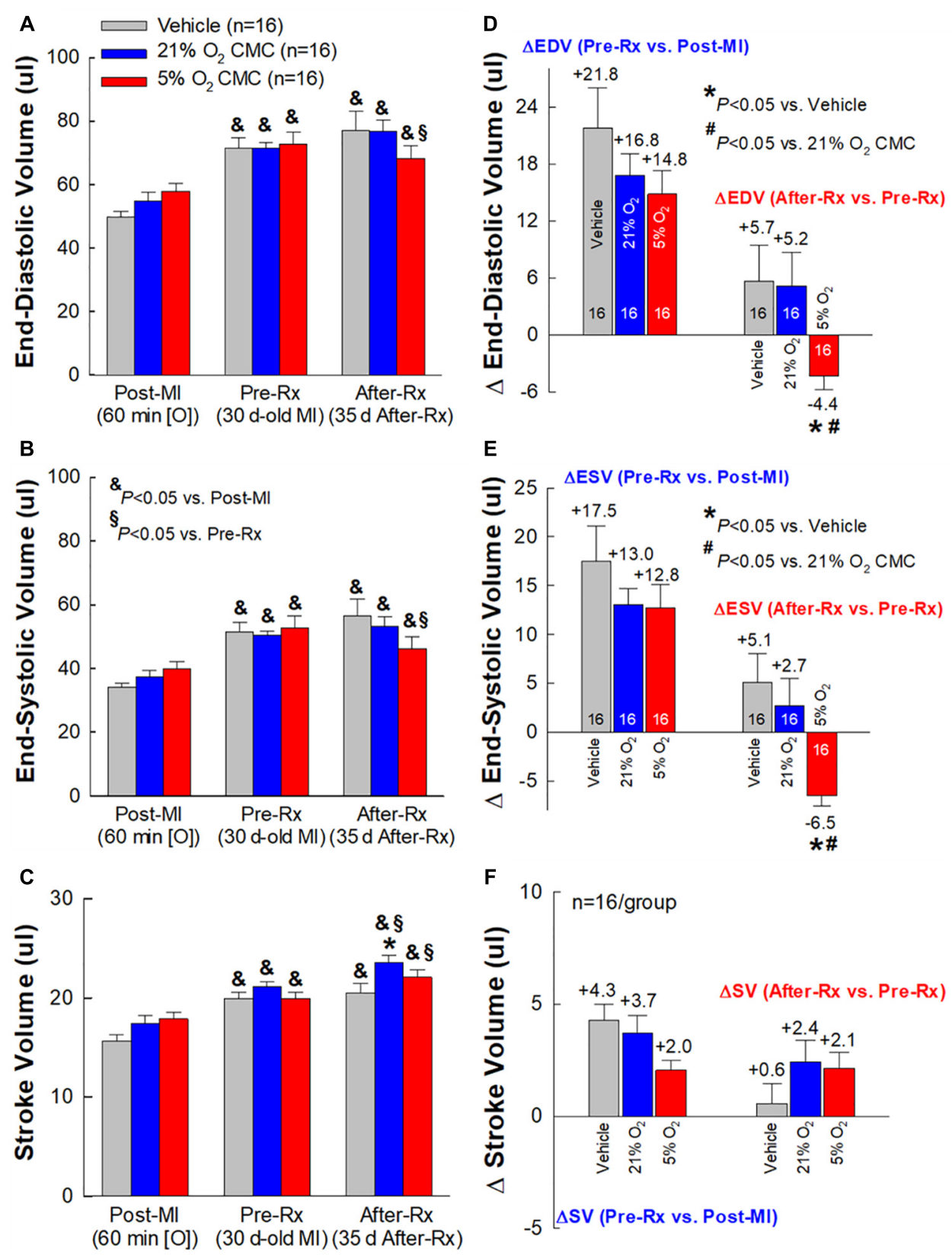

FIGURE 5 | Echocardiographic assessment of LV volumes. Serial echocardiographic measurements of LV end-diastolic volume (EDV) (A), LV end-systolic volume (ESV) (B) and LV stroke volume (SV) (C), were performed 3 days after a 60-min coronary occlusion/reperfusion (Post-MI), 30 days post-MI (before treatment) (Pre-Rx), and 35 days after treatment (After-Rx, 65 days post-MI). The right panels depict the changes in LV EDV (D), ESV (E), and SV (F) between 30 days post-MI (before treatment) (Pre-Rx) and 3 days after Ml (Post-MI) (left), and between 35 days after treatment (After-Rx) and 30 days post-Ml (before treatment) (Pre-Rx) (right). $n=16$ /group. Data are means \pm SEM. ${ }^{\&} P<0.05$ vs. the same group Post-Ml; ${ }^{\S} P<0.05$ vs. the same group Pre-Rx; $P<0.05$ vs. vehicle group at the same time-point; ${ }^{~} P<0.05$ vs. $21 \% \mathrm{O}_{2} \mathrm{CMC}$ group at the same time-point.

content was not statistically significant different in hearts given $21 \% \mathrm{O}_{2}$ grown CMCs compared with vehicle, although it tended to be less in the former (Figure $\mathbf{8 E}$ ). This reduced collagen deposition in the myocardial interstitial space of both risk and non-infarcted regions may have contributed, at least in part, to the functional benefits imparted by $5 \%$ $\mathrm{O}_{2}$ CMC therapy.

\section{DISCUSSION}

The goal of this study was to compare the therapeutic efficacy of CMCs cultured at atmospheric oxygen tension (21\%) (which is the standard method used by almost all investigators that study stem or progenitor cells) with that of CMCs cultured at physiologic oxygen tension (5\%). We used a well-established 

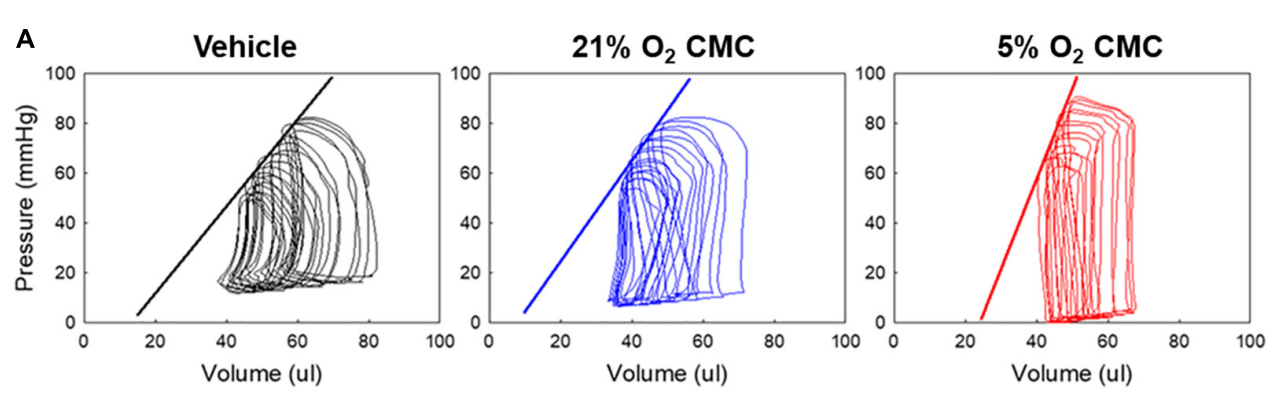

B
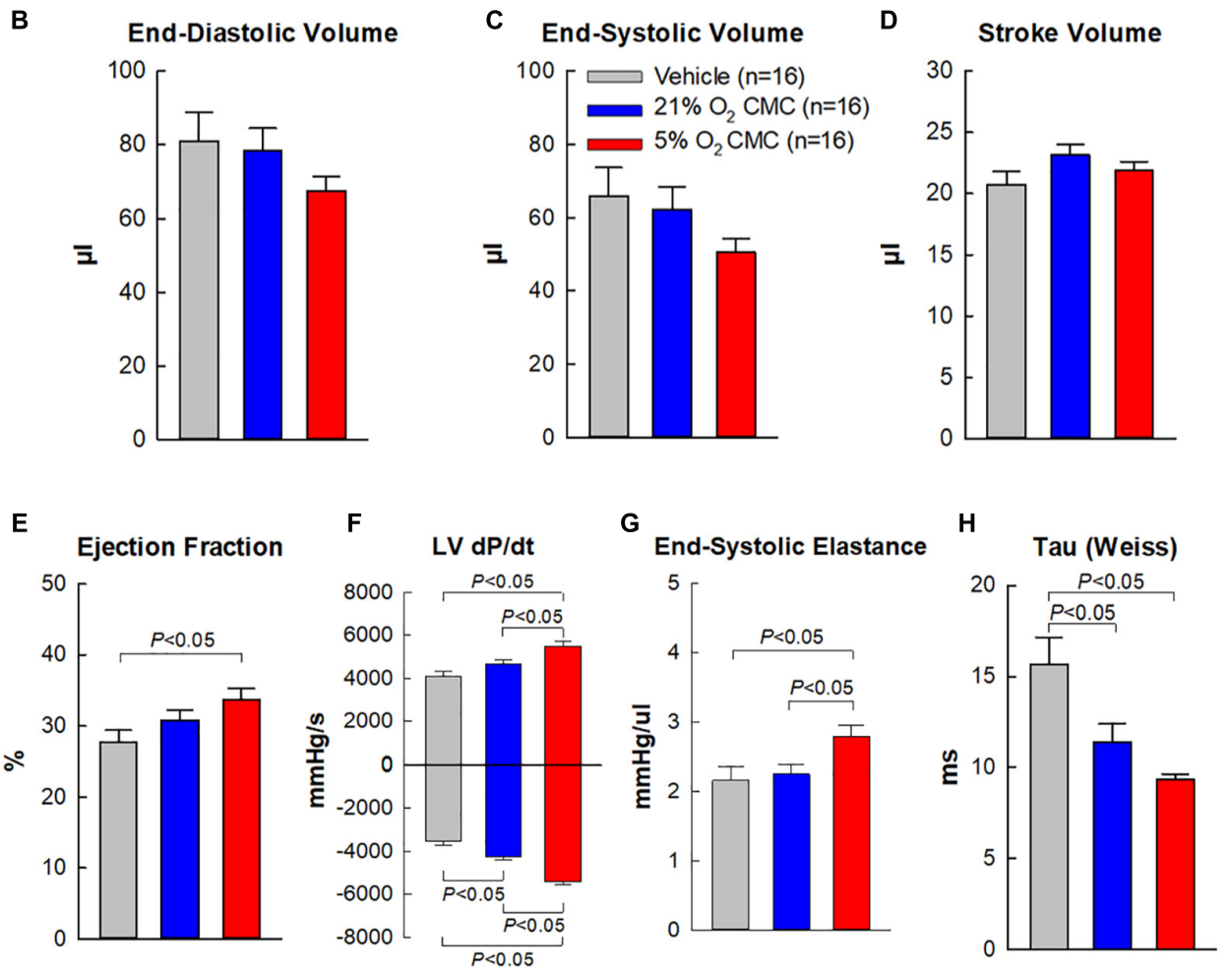

FIGURE 6 | Hemodynamic assessment of cardiac function. Hemodynamic studies were performed with a 1F Millar conductance catheter 39 days after treatment (4 days after the final echocardiographic study), just before euthanasia. (A) Representative LV pressure-volume loops recorded during preload manipulation by brief inferior vena cava occlusions. (B-H) Quantitative analysis of hemodynamic variables. Data are means \pm SEM.

TABLE 2 | LV hypertrophy parameters.

\begin{tabular}{|c|c|c|c|c|}
\hline & Normal control $(n=5)$ & Vehicle $(n=12)$ & $21 \% \mathrm{O}_{2}$ CMCs $(n=11)$ & $5 \% \mathrm{O}_{2}$ CMCs $(n=12)$ \\
\hline LV weight (mg) & $109.4 \pm 7.5^{\star}$ & $126.0 \pm 3.0$ & $115.8 \pm 3.1^{*}$ & $112.2 \pm 3.3^{*}$ \\
\hline Body weight (g) & $24.8 \pm 0.9$ & $23.6 \pm 0.2$ & $23.1 \pm 0.4$ & $24.3 \pm 0.4$ \\
\hline LV weight/Body weight (mg/g) & $4.5 \pm 0.4^{*}$ & $5.4 \pm 0.1$ & $5.0 \pm 0.2$ & $4.6 \pm 0.1^{*}$ \\
\hline LV weight/Tibia length (mg/mm) & $5.9 \pm 0.4^{*}$ & $7.0 \pm 0.2$ & $6.4 \pm 0.2$ & $6.2 \pm 0.2^{*}$ \\
\hline Lung weight/Body weight (mg/g) & $6.8 \pm 0.3$ & $7.4 \pm 0.2$ & $7.3 \pm 0.2$ & $7.1 \pm 0.1$ \\
\hline Lung weight/Tibia length $(\mathrm{mg} / \mathrm{mm})$ & $9.1 \pm 0.6$ & $9.8 \pm 0.2$ & $9.6 \pm 0.2$ & $9.3 \pm 0.2$ \\
\hline
\end{tabular}

${ }^{*} P<0.05$ vs. vehicle group. Data are means \pm SEM.

murine model of chronic ischemic cardiomyopathy in which LV dysfunction is produced by a 30-day old MI (Guo et al., 2017; Nong et al., 2020). This model, characterized by severe and progressive LV dysfunction, LV hypertrophy, and myocardial fibrosis, mimics the common clinical setting of chronic $\mathrm{HF}$ caused by old MIs, which accounts for approximately half of all cases of HF (Jaarsma and Stromberg, 2000; Amirrasouli and Shamsara, 2017; Benjamin et al., 2019).

The salient findings of this study can be summarized as follows. In mice with LV dysfunction caused by a 30-day 
A

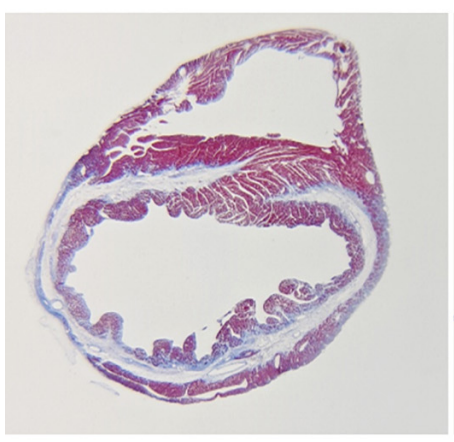

B
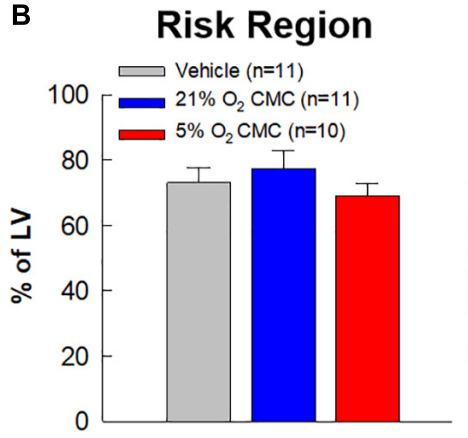

C

$$
\begin{gathered}
\text { Infarcted LV } \\
\text { Wall Thickness }
\end{gathered}
$$

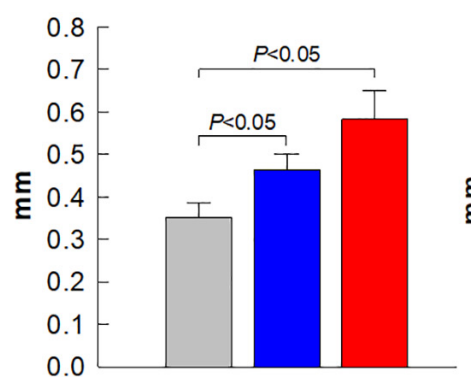

$21 \% \mathrm{O}_{2}$ CMCs

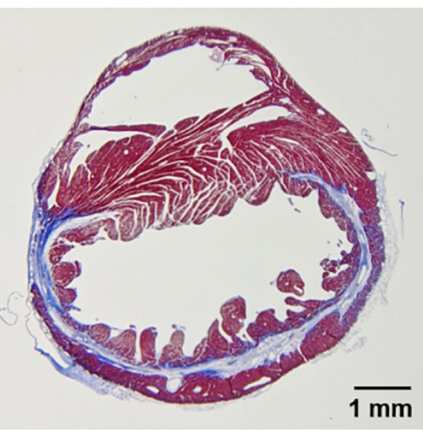

Scar Area

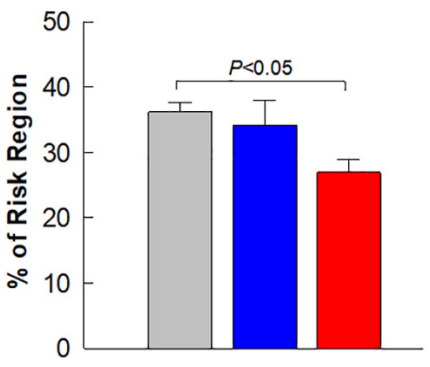

Noninfarcted LV

Wall Thickness

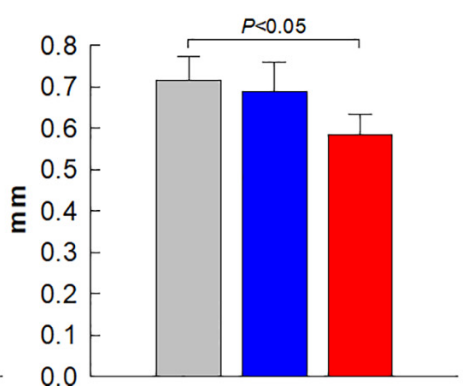

$5 \% \mathrm{O}_{2} \mathrm{CMCs}$

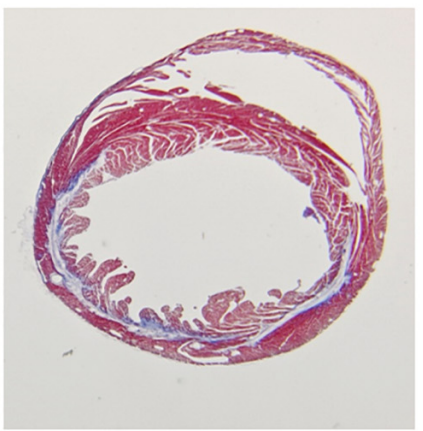

Viable Myocardium

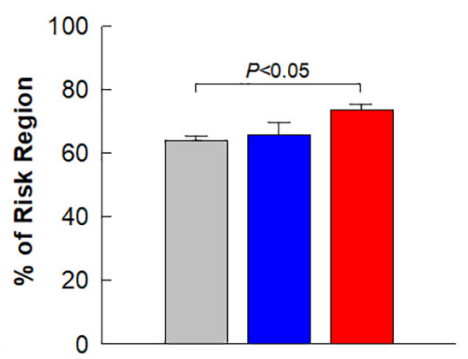

LV Expansion Index

FIGURE 7 | Morphometric analysis of LV remodeling. (A) Representative Masson's trichrome-stained myocardial sections from vehicle, $21 \% \mathrm{O}_{2}$ CMC, or $5 \% \mathrm{O}_{2}$ CMC-treated hearts. Scar tissue and viable myocardium are identified in blue and red, respectively. (B,C) Quantitative analysis of LV morphometric parameters. Data are mean \pm SEM.

old $\mathrm{MI}$, both $21 \%$ and $5 \% \mathrm{O}_{2}$ CMCs improved $\mathrm{LV}$ function; however, the improvement was significantly greater with $5 \% \mathrm{O}_{2}$ CMCs than $21 \% \mathrm{O}_{2}$ CMCs. For example, relative to control mice, the increase in $\mathrm{LV}$ EF was approximately triple in mice treated with $5 \% \mathrm{O}_{2} \mathrm{CMCs}$ compared with mice treated with $21 \% \mathrm{O}_{2}$ CMCs $(5.2 \pm 0.9$ vs. $1.5 \pm 0.7$ absolute EF units, respectively; Figure 4). The evidence we provide for the superior therapeutic efficacy of $5 \% \mathrm{O}_{2} \mathrm{CMCs}$ is robust, because it is based on two independent methods to measure LV function (echocardiography and hemodynamic studies) and on loaddependent as well as independent parameters, both of which point consistently to a greater improvement in hearts treated with 5\% $\mathrm{O}_{2} \mathrm{CMCs}$ (Figures 4-6). This functional improvement afforded by $5 \% \mathrm{O}_{2}$ CMCs was associated with a reversal or prevention of compensatory LV hypertrophy, such that the LV weight/body weight and LV weight/tibia length ratios were similar to those of normal mice (Table 2). The reduction in compensatory LV hypertrophy was likely secondary to improved $\mathrm{LV}$ function. The functional improvement in the $5 \% \mathrm{O}_{2} \mathrm{CMC}$ group was also associated with improved LV structure, as shown by thicker infarct scars, thinner non-infarcted LV walls, and markedly reduced LV expansion index, which likely reflected more viable tissue, less compensatory hypertrophy, and less LV dilatation (Figure 7C). Unlike heart treated with 21\% $\mathrm{O}_{2} \mathrm{CMCs}$, hearts treated with $5 \% \mathrm{O}_{2}$ CMCs exhibited smaller scars and more viable myocardium (Figure 7 ). Since we have previously 


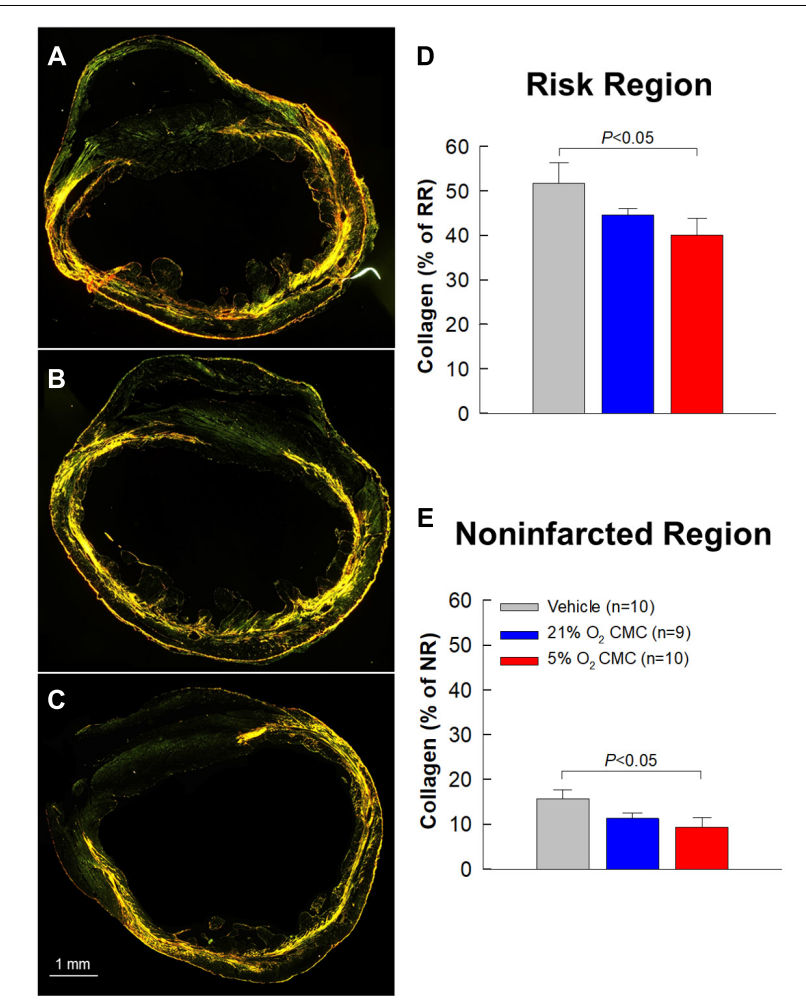

FIGURE 8 | Collagen content in myocardium. (A-C) Representative images of LV sections stained with picrosirius red and analyzed with polarized light microscopy from vehicle, $21 \% \mathrm{O}_{2} \mathrm{CMC}$, or $5 \% \mathrm{O}_{2} \mathrm{CMC}$-treated hearts. (D,E) Quantitative analysis of collagen content in myocardium expressed as a percentage of the risk (D) or non-infarcted $(\mathbf{E})$ region. Data are mean $\pm \mathrm{SEM}$.

demonstrated that CMCs do not engraft in the heart (Guo et al., 2017; Wysoczynski et al., 2017), these results suggest that administration of $5 \% \mathrm{O}_{2} \mathrm{CMCs}$ may have reduced myocyte apoptosis and/or promoted endogenous myocyte proliferation. Finally, administration of $5 \% \mathrm{O}_{2}$ CMCs was associated with less fibrosis in the non-infarcted region (Figure 8E), suggesting that these cells were more effective at limiting extracellular matrix remodeling. Taken together, these results demonstrate that $5 \%$ $\mathrm{O}_{2}$ CMCs are therapeutically superior to $21 \% \mathrm{O}_{2} \mathrm{CMCs}$ in the setting of chronic ischemic cardiomyopathy. Previous studies have shown increased efficacy of other cell types cultured at physiologic oxygen tension (Li T. S. et al., 2011; Amirrasouli and Shamsara, 2017); however, to our knowledge, this is the first report that the therapeutic efficacy of CMCs in vivo is greatly enhanced by culturing them at physiologic oxygen tension (5\%).

Some methodological aspects of this study deserve comment. Mice underwent a 60-min coronary occlusion followed by 30 days of reperfusion; this model of reperfused MI is more clinically relevant than models of permanent occlusion because in contemporary practice almost all patients with MI undergo spontaneous or iatrogenic reperfusion (Benjamin et al., 2019). Reperfusion dramatically alters the evolution and pathophysiology of MI (Basso and Thiene, 2006). The long (60min) coronary occlusion produces large infarcts, sufficient to cause heart failure. This is confirmed by the severe, progressive decline in LV function (Figures 4, 5) and the development of structural abnormalities characteristic of the failing heart, i.e., LV hypertrophy (Table 2) and myocardial fibrosis (Figure 8). We allowed mice to recover for 30 days in order to ensure that the infarct has healed completely and a stable scar has formed. This situation is analogous to that of patients with coronary artery disease who have scars caused by old MIs and develop heart failure as a consequence of the loss of cardiac muscle. At 30 days after MI, vehicle or CMCs were delivered directly into the LV cavity via percutaneous injection under echocardiographic guidance. This method is much less traumatic than repeated thoracotomies, results in much higher survival rates, and enables CMCs to be delivered close to the coronary arteries (Guo et al., 2017; Nong et al., 2020). Using this method, we have previously documented that a significant number of cells are retained in the heart at 1 day after injection, comparable to or greater than that seen after intramyocardial and intracoronary injection (Guo et al., 2017).

The robustness of our conclusions is supported by a number of considerations. In almost all rodent studies, LV function is assessed only with load-dependent measurements. However, there are distinct advantages in using load-independent parameters. Unlike EF or fractional shortening, loadindependent parameters are not affected by uncontrollable variables such as venous return, ventricular dimensions, aortic pressure, LV compliance, peripheral resistance, etc., which vary continuously and unpredictably in intact animals (Schertel, 1998; Lindsey et al., 2018). Consequently, load-independent parameters are more reliable and meaningful. Among these, particular importance should be assigned to end-systolic elastance (Ees), which is often regarded as the gold-standard for assessing cardiac contractility (Schertel, 1998; Lindsey et al., 2018). Therefore, in this study the measurements of Ees could be viewed as the most important indicator of the therapeutic actions of transplanted cells. As shown in Figure 6G, in the 5\% $\mathrm{O}_{2}$ CMCs group Ees was significantly greater not only compared with the vehicle group but also compared with the $21 \% \mathrm{O}_{2}$ CMCs group. The superiority of $5 \% \mathrm{O}_{2} \mathrm{CMCs}$ is further corroborated by the structural results. As shown in Figures 7, 8 and Table 2, structural improvement, i.e., a reduction in scar size, LV hypertrophy, and collagen content and an increase in viable myocardium, were observed only in hearts treated with $5 \% \mathrm{O}_{2}$ CMCs. Taken together, these diverse and independent results support the conclusion that $5 \% \mathrm{O}_{2} \mathrm{CMCs}$ were more efficacious than $21 \% \mathrm{O}_{2}$ CMCs.

The mechanism(s) responsible for the superior therapeutic efficacy of $5 \% \quad \mathrm{O}_{2}$ CMCs vs. $21 \% \quad \mathrm{O}_{2}$ CMCs remain to be elucidated. We have previously demonstrated that CMCs do not engraft in the heart and do not differentiate into new cardiomyocytes (Guo et al., 2017; Wysoczynski et al., 2017) and thus (similar to other cell types) (Tokita et al., 2016) act via paracrine mechanisms. The exact nature of these paracrine actions has not yet been ascertained for any mesenchymal cell type used heretofore (Banerjee et al., 2018). The increased resistance of $5 \% \mathrm{O}_{2} \mathrm{CMCs}$ to severe hypoxia and their much higher proliferation rate in vitro as well as their enhanced 
telomerase activity and elongated telomere length (Bolli et al., 2021) imply that, after transplantation in vivo, $5 \% \mathrm{O}_{2} \mathrm{CMCs}$ will be more likely to survive the harsh environment of the infarcted heart and will continue to multiply at a higher rate, which should result in greater cell numbers and thus greater therapeutic effects. Our finding that treatment with $5 \% \mathrm{O}_{2}$ CMCs was associated with an increase in viable myocardium (Figure 7) suggests possible antiapoptotic actions and/or increase proliferation of endogenous myocytes. Our finding of decreased collagen content in both the risk and non-infarcted regions of hearts treated with $5 \% \mathrm{O}_{2}$ CMCs (Figure 8) offers another possible explanation, since increased collagen deposition resulting in fibrosis impairs contractile function. Further studies will be necessary to test these hypotheses and determine the mechanisms that account for the superiority of $5 \% \mathrm{O}_{2} \mathrm{CMCs}$. This uncertainty regarding mechanism(s) of action is common to essentially all cell types that have been tested for the treatment of heart failure (Wysoczynski et al., 2018).

\section{CONCLUSION}

In conclusion, this study shows for the first time that, compared with the commonly used atmospheric oxygen tension (21\%), the use of physiologic oxygen tension (5\%) to culture CMCs markedly increases their therapeutic efficacy in a murine model of chronic ischemic cardiomyopathy. These results are important not only because they enhance the therapeutic potential of CMCs but also because culture at $5 \% \mathrm{O}_{2}$ enables greater numbers of cells to be produced in a shorter time, thereby reducing costs and effort and limiting cell senescence (Bolli et al., 2021). Due to the similarity between CMCs and other stem/progenitor cells, it is likely to these results may apply to other types of cells being studied in experimental or clinical trials but still cultured at atmospheric $\mathrm{O}_{2}$ tension. Thus, the present study has potentially vast implications because it supports a paradigm shift in the field of cell therapy. The standard method to culture most stem/progenitor cells, including CMCs, is to use $21 \% \mathrm{O}_{2}$ tension rather than the physiologic oxygen tension in the tissue. Our results suggest this method needs to be changed and that for CMCs, and probably for other types of stem/progenitor cells as well, physiologic oxygen tension needs to be used to maximize therapeutic efficacy, both in preclinical and clinical studies.

\section{REFERENCES}

Amirrasouli, M. M., and Shamsara, M. (2017). Comparing the in vivo and in vitro effects of hypoxia $(3 \% \mathrm{O}(2))$ on directly derived cells from murine cardiac explants versus murine cardiosphere derived cells. J. Stem Cells Regen. Med. 13, 35-44. doi: 10.46582/jsrm. 1302007

Banerjee, M. N., Bolli, R., and Hare, J. M. (2018). Clinical Studies of Cell Therapy in Cardiovascular Medicine: recent Developments and Future Directions. Circ. Res. 123, 266-287. doi: 10.1161/circresaha.118.311217

Basso, C., and Thiene, G. (2006). The pathophysiology of myocardial reperfusion: a pathologist's perspective. Heart 92, 1559-1562. doi: 10.1136/hrt.2005.086959

Benjamin, E. J., Muntner, P., Alonso, A., Bittencourt, M. S., Callaway, C. W., Carson, A. P., et al. (2019). Heart Disease and Stroke Statistics-2019 Update: a Report From the American Heart Association. Circulation 139, e56-e528.

\section{DATA AVAILABILITY STATEMENT}

The original contributions presented in the study are included in the article, further inquiries can be directed to the corresponding author.

\section{ETHICS STATEMENT}

The animal study was reviewed and approved by Institutional Animal Care and Use Committee, University of Louisville.

\section{AUTHOR CONTRIBUTIONS}

RB did cell culture, acquired cell images, and conducted echocardiographic studies and analyses as well as histological procedure. AA and $\mathrm{SH}$ performed histological sectioning, staining, and image analyses. CD did cell culture partially for cell transplantation. AT, YN, and YG performed the surgical procedures, echocardiography-guided intraventricular cell transplantation, echocardiographic and hemodynamic studies, and analyses. QL partially performed experiments, designed all the studies, analyzed and interpreted the data, prepared figures, and wrote and finalized the manuscript. All authors have reviewed and approved the final version of the manuscript and meet the International Committee for Medical Journal Editors (ICMJE) authorship criteria.

\section{FUNDING}

This work was supported by National Institutes of Health Grants P01 HL078825 and UM1 HL113530.

\section{ACKNOWLEDGMENTS}

We thank Dr. Marcin Wysoczynski and Ms. Marjan Nasr for providing the original CMCs at passage 2 and cell culture media.

Bennett, W. R., Yawn, D. H., Migliore, P. J., Young, J. B., Pratt, C. M., Raizner, A. E., et al. (1987). Activation of the complement system by recombinant tissue plasminogen activator. J. Am. Coll. Cardiol. 10, 627-632.

Bolli, R. A., Dasari, C., Arshia, A., Devadoss, D., Guo, Y., Ashraf, U., et al. (2021). Physiological Oxygen Tension Enhances Competence and Functional Properties of Murine Cardiac Mesenchymal Cells. Stem Cell Rev. Rep. [Online ahead of print]. doi: 10.1007/s12015-020-10106-6

Dawn, B., Guo, Y., Rezazadeh, A., Huang, Y., Stein, A. B., Hunt, G., et al. (2006). Postinfarct cytokine therapy regenerates cardiac tissue and improves left ventricular function. Circ. Res. 98, 1098-1105. doi: 10.1161/01.res.0000218454. 76784.66

Dawn, B., Tiwari, S., Kucia, M. J., Zuba-Surma, E. K., Guo, Y., Sanganalmath, S. K., et al. (2008). Transplantation of bone marrow-derived very small embryoniclike stem cells attenuates left ventricular dysfunction and remodeling after 
myocardial infarction. Stem Cells 26, 1646-1655. doi: 10.1634/stemcells.20070715

Drela, K., Sarnowska, A., Siedlecka, P., Szablowska-Gadomska, I., Wielgos, M., Jurga, M., et al. (2014). Low oxygen atmosphere facilitates proliferation and maintains undifferentiated state of umbilical cord mesenchymal stem cells in an hypoxia inducible factor-dependent manner. Cytotherapy 16, 881-892. doi: 10.1016/j.jcyt.2014.02.009

Earle, W. R., Schilling, E. L., Stark, T. H., Straus, N. P., Brown, M. F., and Shelton, E. (1943). Production of Malignancy in Vitro. IV. The Mouse Fibroblast Cultures and Changes Seen in the Living Cells. JNCI: J. Natl. Cancer Inst. 4, 165-212.

Gao, S., Ho, D., Vatner, D. E., and Vatner, S. F. (2011). Echocardiography in Mice. Curr. Protoc. Mouse Biol. 1, 71-83.

Gottdiener, J. S., Bednarz, J., Devereux, R., Gardin, J., Klein, A., Manning, W. J., et al. (2004). American Society of Echocardiography recommendations for use of echocardiography in clinical trials. J. Am. Soc. Echocardiogr. 17, 1086-1119. doi: 10.1016/s0894-7317(04)00675-3

Guo, Y., Nong, Y., Li, Q., Tomlin, A., Kahlon, A., Gumpert, A., et al. (2020). Comparison of One and Three Intraventricular Injections of Cardiac Progenitor Cells in a Murine Model of Chronic Ischemic Cardiomyopathy. Stem Cell Rev. Rep. 17, 604-615. doi: 10.1007/s12015-020-10063-0

Guo, Y., Wysoczynski, M., Nong, Y., Tomlin, A., Zhu, X., Gumpert, A. M., et al. (2017). Repeated doses of cardiac mesenchymal cells are therapeutically superior to a single dose in mice with old myocardial infarction. Basic Res. Cardiol. 112:18.

Jaarsma, T., and Stromberg, A. (2000). Heart failure clinics in Europe. Prog. Cardiovasc. Nurs. 15, 67-68.

Jagannathan, L., Cuddapah, S., and Costa, M. (2016). Oxidative stress under ambient and physiological oxygen tension in tissue culture. Curr. Pharmacol. Rep. 2, 64-72. doi: 10.1007/s40495-016-0050-5

Li, Q., Bolli, R., Qiu, Y., Tang, X. L., Guo, Y., and French, B. A. (2001). Gene therapy with extracellular superoxide dismutase protects conscious rabbits against myocardial infarction. Circulation 103, 1893-1898. doi: 10.1161/01.cir. 103.14.1893

Li, Q., Guo, Y., Ou, Q., Chen, N., Wu, W. J., Yuan, F., et al. (2011). Intracoronary administration of cardiac stem cells in mice: a new, improved technique for cell therapy in murine models. Basic Res. Cardiol. 106, 849-864. doi: 10.1007/ s00395-011-0180-1

Li, T. S., Cheng, K., Malliaras, K., Matsushita, N., Sun, B., Marbán, L., et al. (2011). Expansion of human cardiac stem cells in physiological oxygen improves cell production efficiency and potency for myocardial repair. Cardiovasc. Res. 89, 157-165. doi: 10.1093/cvr/cvq251

Li, X. Y., Mccay, P. B., Zughaib, M., Jeroudi, M. O., Triana, J. F., and Bolli, R. (1993). Demonstration of free radical generation in the "stunned" myocardium in the conscious dog and identification of major differences between conscious and open-chest dogs. J. Clin. Invest. 92, 1025-1041. doi: 10.1172/jci11 6608

Lindsey, M. L., Bolli, R., Canty, J. M. Jr., Du, X.-J., Frangogiannis, N. G., Frantz, S., et al. (2018). Guidelines for experimental models of myocardial ischemia and infarction. Am. J. Physiol.-Heart Circ. Physiol. 314, H812-H838.

Mas-Bargues, C., Sanz-Ros, J., Román-Domínguez, A., Inglés, M., GimenoMallench, L., El Alami, M., et al. (2019). Relevance of Oxygen Concentration in Stem Cell Culture for Regenerative Medicine. Int. J. Mol. Sci. 20:1195. doi: 10.3390/ijms20051195

Mehra, P., Guo, Y., Nong, Y., Lorkiewicz, P., Nasr, M., Li, Q., et al. (2018). Cardiac mesenchymal cells from diabetic mice are ineffective for cell therapy-mediated myocardial repair. Basic Res. Cardiol. 113:46.
Mohyeldin, A., Garzon-Muvdi, T., and Quinones-Hinojosa, A. (2010). Oxygen in stem cell biology: a critical component of the stem cell niche. Cell Stem Cell 7, 150-161. doi: 10.1016/j.stem.2010.07.007

Nong, Y., Guo, Y., Tomlin, A., Zhu, X., Wysoczynski, M., Li, Q., et al. (2020). Echocardiography-guided percutaneous left ventricular intracavitary injection as a cell delivery approach in infarcted mice. Mol. Cell Biochem. 476, 2135-2148. 2020.2003.2031.018358, doi: 10.1007/s11010-021-04077-6

Roy, S., Khanna, S., Bickerstaff, A. A., Subramanian, S. V., Atalay, M., Bierl, M., et al. (2003). Oxygen sensing by primary cardiac fibroblasts: a key role of p21(Waf1/Cip1/Sdi1). Circ. Res. 92, 264-271. doi: 10.1161/01.res.0000056770. 30922.e6

Schertel, E. R. (1998). Assessment of Left-Ventricular Function. Thorac. Cardiovasc. Surg. 46, 248-254.

Schulman, I. H., Balkan, W., and Hare, J. M. (2018). Mesenchymal Stem Cell Therapy for Aging Frailty. Front. Nutr. 5:108. doi: 10.3389/fnut.2018.00108

Tang, X. L., Li, Q., Rokosh, G., Sanganalmath, S. K., Chen, N., Ou, Q., et al. (2016). Long-Term Outcome of Administration of c-kit(POS) Cardiac Progenitor Cells After Acute Myocardial Infarction: transplanted Cells Do not Become Cardiomyocytes, but Structural and Functional Improvement and Proliferation of Endogenous Cells Persist for at Least One Year. Circ. Res. 118, 1091-1105. doi: 10.1161/circresaha.115.307647

Tang, X. L., Nakamura, S., Li, Q., Wysoczynski, M., Gumpert, A. M., Wu, W. J., et al. (2018). Repeated Administrations of Cardiac Progenitor Cells Are Superior to a Single Administration of an Equivalent Cumulative Dose. J. Am. Heart Assoc. 7:e007400.

Tang, X. L., Qiu, Y., Park, S. W., Sun, J. Z., Kalya, A., and Bolli, R. (1996). Time course of late preconditioning against myocardial stunning in conscious pigs. Circ. Res. 79, 424-434. doi: 10.1161/01.res.79.3.424

Tokita, Y., Tang, X. L., Li, Q., Wysoczynski, M., Hong, K. U., Nakamura, S., et al. (2016). Repeated Administrations of Cardiac Progenitor Cells Are Markedly More Effective Than a Single Administration: a New Paradigm in Cell Therapy. Circ. Res. 119, 635-651. doi: 10.1161/circresaha.116.308937

Triana, J. F., Li, X. Y., Jamaluddin, U., Thornby, J. I., and Bolli, R. (1991). Postischemic myocardial "stunning". Identification of major differences between the open-chest and the conscious dog and evaluation of the oxygen radical hypothesis in the conscious dog. Circ. Res. 69, 731-747. doi: 10.1161/01. res.69.3.731

Wysoczynski, M., Guo, Y., Moore, J. B. T., Muthusamy, S., Li, Q., Nasr, M., et al. (2017). Myocardial Reparative Properties of Cardiac Mesenchymal Cells Isolated on the Basis of Adherence. J. Am. Coll. Cardiol. 69, 1824-1838. doi: 10.1016/j.jacc.2017.01.048

Wysoczynski, M., Khan, A., and Bolli, R. (2018). New Paradigms in Cell Therapy: repeated Dosing, Intravenous Delivery, Immunomodulatory Actions, and New Cell Types. Circ. Res. 123, 138-158. doi: 10.1161/circresaha.118.313251

Conflict of Interest: The authors declare that the research was conducted in the absence of any commercial or financial relationships that could be construed as a potential conflict of interest.

Copyright (C) 2021 Bolli, Arshia, Hassan, Dasari, Nong, Guo, Tomlin and Li. This is an open-access article distributed under the terms of the Creative Commons Attribution License (CC BY). The use, distribution or reproduction in other forums is permitted, provided the original author(s) and the copyright owner(s) are credited and that the original publication in this journal is cited, in accordance with accepted academic practice. No use, distribution or reproduction is permitted which does not comply with these terms. 